\title{
Fatores de risco associados à ocorrência de carcinoma de células escamosas em ruminantes e equinos no semiárido da Paraíba ${ }^{1}$
}

\author{
Fabricio K. de L. Carvalho ${ }^{2}$, Antônio F.M. Dantas ${ }^{2}$, Franklin Riet-Correa ${ }^{2}$, \\ Eldinê G. de Miranda Neto ${ }^{2}$, Sara V.D. Simões ${ }^{2}$ e Sérgio S. Azevedo ${ }^{2}$
}

\begin{abstract}
Carvalho F.K.L., Dantas A.F.M., Riet-Correa F., Miranda Neto E.G., Simões S.V.D. \& Azevedo S.S. 2012. [Risk factors associated with the squamous cell carcinoma occurrence in ruminants and equine in the semiarid of the Paraíba.] Fatores de risco associados à ocorrência de carcinoma de células escamosas em ruminantes e equinos no semiárido da Paraíba. Pesquisa Veterinária Brasileira 32(9):881-886. Hospital Veterinário, Laboratório de Patologia Animal, CSTR, Universidade Federal de Campina Grande, Campus de Patos, Avenida Universitária s/n, Bairro Santa Cecília, Patos, PB 58708-110, Brazil. E-mail: dantas.af@uol.com.br

This paper describes the frequency of squamous cell carcinoma (SCC) diagnosed at the Laboratory (LPA) of Animal Pathology, Veterinary Hospital of the Federal University of Campina Grande (UFCG), in cattle, sheep, goats, and horses in the semiarid region of Paraíba, Brazil, from 1983 to 2010, analyzing epidemiological data and risk factors. We performed the analysis of risk factors, by the chi-square test, considering variables such as species, breed, sex, age and location of the tumor mass. During the period, 3153 diagnoses were recorded from biopsies and necropsies. From these, 81 cases $(2.7 \%)$ were squamous cell carcinomas. The frequency by species was $4 \%(42 / 1052)$ in cattle, $2.5 \%(15 / 603)$ in horses, $1.7 \%(12 / 709)$ in sheep, and 1.5\% (12/789) in goats, being significantly higher in cattle $(\mathrm{p}<0.001)$. All cases showed histological features of SCC, varying only the degree of cell differentiation. In cattle and goats, the frequency of SCC was significantly higher in adult animals $(\mathrm{p}<0.001$ and $<0.005$, respectively). In cattle the preferred location was in the eyes and periocular region $(p<0.001)$, in sheep in the skin $(p=0.018)$, especially the head. In other species no significant differences were found in the tumor location. It is suggested that the higher frequency of SCC in cattle is due to the constitution of the herds, formed predominantly by females of the Holstein breed.
\end{abstract}

INDEX TERMS: Neoplasms of the skin, animal production, risk factors.

RESUMO.- Neste trabalho descreve-se a frequência de carcinomas de células escamosas diagnosticados pelo Laboratório de Patologia Animal (LPA) do Hospital Veterinário da Universidade Federal de Campina Grande (UFCG) em bovinos, ovinos, caprinos e equinos no semiárido da Paraíba, durante o período de 1983 a 2010, analisando dados

\footnotetext{
${ }^{1}$ Recebido em 2 de maio de 2012.

Aceito para publicação em 4 de junho de 2012.

Parte da Dissertação de Mestrado do primeiro autor. Programa de Pós-Graduação em Medicina Veterinária, Universidade Federal de Campina Grande (UFCG), Av. Universitária s/n, Bairro Santa Cecília, Patos, PB 58708-110, Brasil.

${ }^{2}$ Hospital Veterinário, Centro de Saúde e Tecnologia Rural (CSTR), Universidade Federal de Campina Grande, Patos, PB 58708-110, Brasil. *Autor para correspondência: dantas.af@uol.com.br
}

epidemiológicos e fatores de risco. Foi realizada a análise dos fatores de risco, mediante o teste de qui-quadrado de aderência, considerando como variáveis espécie, raça, sexo, idade e localização da massa tumoral. Durante o período foram registrados 3.153 diagnósticos provenientes de biópsias e necropsias. Destes, 81 casos $(2,7 \%)$ foram de carcinomas de células escamosas. A frequência por espécie foi de $4 \%(42 / 1052)$ em bovinos, 2,5\% (15/603) em equinos, $1,7 \%(12 / 709)$ em ovinos e 1,5\% (12/789) em caprinos, sendo significativamente maior em bovinos $(\mathrm{p}<0,001)$. Todos os casos apresentavam características histológicas de CCE, variando apenas o grau de diferenciação celular. Em bovinos e caprinos, a frequência do tumor foi significativamente maior em animais adultos $(p<0,001$ e $p<0,005$, respectivamente). Nos bovinos a localização preferencial 
foi em olhos e região periocular $(p<0,001)$ e nos ovinos na pele $(p=0,018)$, principalmente na cabeça, enquanto que nas outras espécies não foram encontradas diferenças significantes na localização do tumor. Sugere-se que a maior frequência de CCE em bovinos deve-se à constituição do rebanho, formado predominantemente por fêmeas da raça Holandesa.

TERMOS DE INDEXAÇÃO: Neoplasias de pele, animais de produção, fatores de risco.

\section{INTRODUÇÃO}

Carcinoma de células escamosas (CCE) são tumores malignos de queratinócitos relatados em várias partes do mundo. Esses tumores são comumente encontrados em bovinos, equinos, cães e gatos, mas incomuns em ovinos e raros em caprinos (Meuten 2002). Seu desenvolvimento está relacionado à exposição prolongada de raios ultravioleta em pele despigmentada, sem pelos e com lesões prévias. São responsáveis por significativas perdas econômicas em bovinos em países da América do Norte (Tsujita \& Plummer 2010).

Algumas raças de bovinos como Hereford, Simmental e Holandesa apresentam maior predisposição à ocorrência de CCE (Meuten 2002, Ramos et al. 2007, Tsujita \& Plummer 2010). Em bovinos e equinos esta neoplasia é observada nas junções mucocutâneas, principalmente na região de pálpebras e genitálias, enquanto em ovinos e caprinos observa-se mais frequentemente na orelha (Meuten 2002, Smith 2006, Scott \& Miller 2011). Na África do Sul, em cabras da raça Saanen e Angorá esta neoplasia é encontrada mais no úbere e geralmente vem associada a papilomas (Smith 2006).

Macroscopicamente, os CCEs podem apresentar aspecto proliferativo, semelhante a couve-flor ou erosivo recoberto por crostas que não cicatrizam. São ligeiramente elevados, muitos com base ampla, onde à medida que o tumor torna-se invasivo na derme, a lesão tende a ser mais firme (Meuten 2002, Smith 2006, Fernandes 2007). É um tumor localmente invasivo e metástases geralmente ocorre para linfonodos regionais (Meuten 2002).

Microscopicamente, as células neoplásicas apresentam núcleos grandes, centrais, muitas vezes vesiculosos, com vários nucléolos e citoplasma proeminente (Meuten 2002), que se arranjam formando ilhas ou cordões de células epidérmicas proliferadas ou não, que se estendem através da derme, demonstrando um grau variável de diferenciação neoplásica (Fernandes 2007, Ramos et al. 2007). Mitoses são comuns, entretanto são mais frequentes e mais atípicas nos carcinomas pobremente diferenciados (Meuten 2002).

Os CCEs bem diferenciados apresentam células dispostas em cordões ou espirais com centros queratinizados, muitos em forma de pérolas lamelares, e/ou dispostos em pontes intercelular podendo apresentar queratinização individual. Os CCEs diferenciados apresentam várias células com queratinização individual e menos frequentemente pérolas e pontes intercelulares. Nos indiferenciados é difícil reconhecer as células tumorais como sendo originadas de queratinócitos. A queratinização, quando presente, restringe-se à queratinização individual acompanhada de cariorexia e ausência de picnose (Weiss \& Frese 1974). Hiperplasia da epiderme, hiperqueratose, acantose, paraqueratose e/ou ortoquetatose, displasia de queratinócitos, infiltrado neutrófilo na parte superficial do tumor e infiltrado linfoplasmocitário nas partes mais profundas do tumor, também podem ser observados (Meuten 2002).

Estudos realizados mediante levantamento de neoplasias com animais de produção em regiões da África (Murray 1968, Bastianello 1982), Inglaterra (Cotchin 1960), Israel (Yeruham et al. 1999), Canadá (Plummer 1956, Misdorp 1967) Holanda (Dukes et al. 1982) e Estados Unidos (Valentine 2006, Scott \& Miller 2011) demostram que o CCE é a principal ou uma das principais neoplasias em animais de produção.

No Brasil existem poucas pesquisas relacionadas a estudos retrospectivos com neoplasias em animais de produção. Em algumas regiões do Brasil os CCEs estão entre as neoplasias mais frequentes nos animais de produção. No Rio Grande do Sul, estudos realizados no Laboratório Regional de Diagnóstico da Faculdade de Veterinária da Universidade Federal de Pelotas (UFPel), o CCE foi o tumor mais frequente em ovinos e o segundo em bovinos e equinos, perdendo apenas para linfossarcoma e sarcoide, respectivamente (Ramos et al. 2007, 2008). Os casos de CCEs diagnosticados em bovinos no Laboratório de Patologia Veterinária da Universidade Federal de Santa Maria foram mais frequentes no trato digestivo e estavam associados a ingestão de Pteridium aquilinum (samambaia), seguidos, em frequência, pelos CCE de olho e pele (Lucena et al. 2010). Em equinos o CCE foi o segundo tumor mais frequente, depois do sarcoide (Souza et al. 2011). Na Paraíba, em ovinos e caprinos, os CCEs foram a terceira doença de pele mais frequente, perdendo apenas para os casos de miíase e ectima contagioso (Macêdo et al. 2008). Casos de CCE na região perineal também têm sido descritos em cabras no estado do Pará (Barbosa et al. 2009).

Esse trabalho teve como objetivo determinar a frequência de casos de carcinomas de células escamosas em bovinos, ovinos, caprinos e equinos, diagnosticados no Laboratório de Patologia Animal (LPA) do Hospital Veterinário da Universidade Federal de Campina Grande (UFCG), durante o período de 1983 a 2010, avaliando dados epidemiológicos e fatores de risco.

\section{MATERIAL E MÉTODOS}

Foi realizado um levantamento dos tumores diagnosticados no LPA durante o período de 1983 a 2010, selecionando todos os casos de CCEs diagnosticados nas necropsias e biópsias de ruminantes e equinos nesse período. As fichas individuais dos animais afetados foram revisadas, como também as lâminas histológicas. Algumas lâminas antigas foram descoradas com ácido acético e recoradas pela técnica de hematoxilina e eosina. Quando necessário, os materiais arquivados em blocos de parafina eram reencaminhados para confecção de novas lâminas para exame mais detalhado em microscopia óptica.

Em relação à idade os ruminantes foram agrupados em jovens (animais até 2 anos), adultos (acima de 2 anos e até 7 anos) e senis (acima de 7 anos). Já os equinos, foram considerados animais jovens até 5 anos, animais adultos acima de 5 anos até 14 anos e 
senis acima de 14 anos. Em relação aos locais de incidência, os tumores foram divididos em região orbitária (globo ocular e toda a região que circunda o olho), reprodutor masculino (áreas ligadas ao prepúcio e pênis), reprodutor feminino (áreas ligadas a vulva e períneo) e pele (todas as outras áreas restantes).

Foi realizada análise de fatores de risco em relação aos casos diagnosticados como carcinoma de células escamosas em um estudo caso controle, utilizando-se o teste de qui-quadrado, considerando como casos todos os animais com neoplasia e como controles o mesmo número de animais escolhidos ao acaso entre os animais encaminhados ao LPA por outras causas e isentos de neoplasia. As variáveis consideradas foram espécie, raça, sexo e idade. Para a avaliação da frequência da localização da massa tumoral foi utilizado o teste de qui-quadrado de aderência. Informações que não constavam na ficha clínica foram excluídas da análise estatística.

Os carcinomas de células escamosas foram classificados seguindo os padrões histológicos definidos pela Organização Mundial de Saúde e o livro de Tumores de Animais Domésticos (Weiss \& Frese 1974, Meuten 2002).

\section{RESULTADOS}

No período de Janeiro de 1983 a dezembro de 2010 foram registrados 3.153 diagnósticos provenientes de biópsias e necropsias em animais de produção (ruminantes e equinos) no LPA/UFCG/Campus de Patos-PB. Destes, 177 neoplasias $(5,6 \%)$, sendo 81 casos $(45,8 \%)$ de carcinomas de células escamosas. Do total de material recebido $(3.153$ diagnósticos) de ruminantes e equinos, os CCEs representaram 2,6\%. A frequência por espécie foi de $4 \%(42 / 1052)$ em bovinos, 2,5\% (15/603) em equinos, 1,7\% (12/709) em ovinos e 1,5\% (12/789) em caprinos, sendo significativamente maior em bovinos $(<0,001)$.

A localização mais frequente nos bovinos e equinos foi a região orbitária (Figs. 1 e 2), enquanto que nos pequenos ruminantes o CCE foi mais observado na pele da cabeça de ovinos e na vulva de cabras (Fig. 3). Em cinco bovinos foram observados metástases em outros órgãos. Dois bovinos apresentaram metástases no linfonodo mandibular e pulmão, outro caso no pulmão, diafragma e coração, outro nos linfonodos parotídeos, ilíacos, mesentéricos e mediastínicos, pulmão, diafragma e coração, e no último caso havia metástases na glândula parótida e na veia jugular (Fig. 1B). Em todos os casos relacionados, as características histológicas observadas eram compatíveis com CCE, variando apenas o grau de diferenciação celular. A maioria deles foi caracterizado como CCE bem diferenciado, formando aglomerados de células tumorais com queratinização laminar concêntrica, formando pérolas de queratina (Fig. 1D) e queratinização individual.
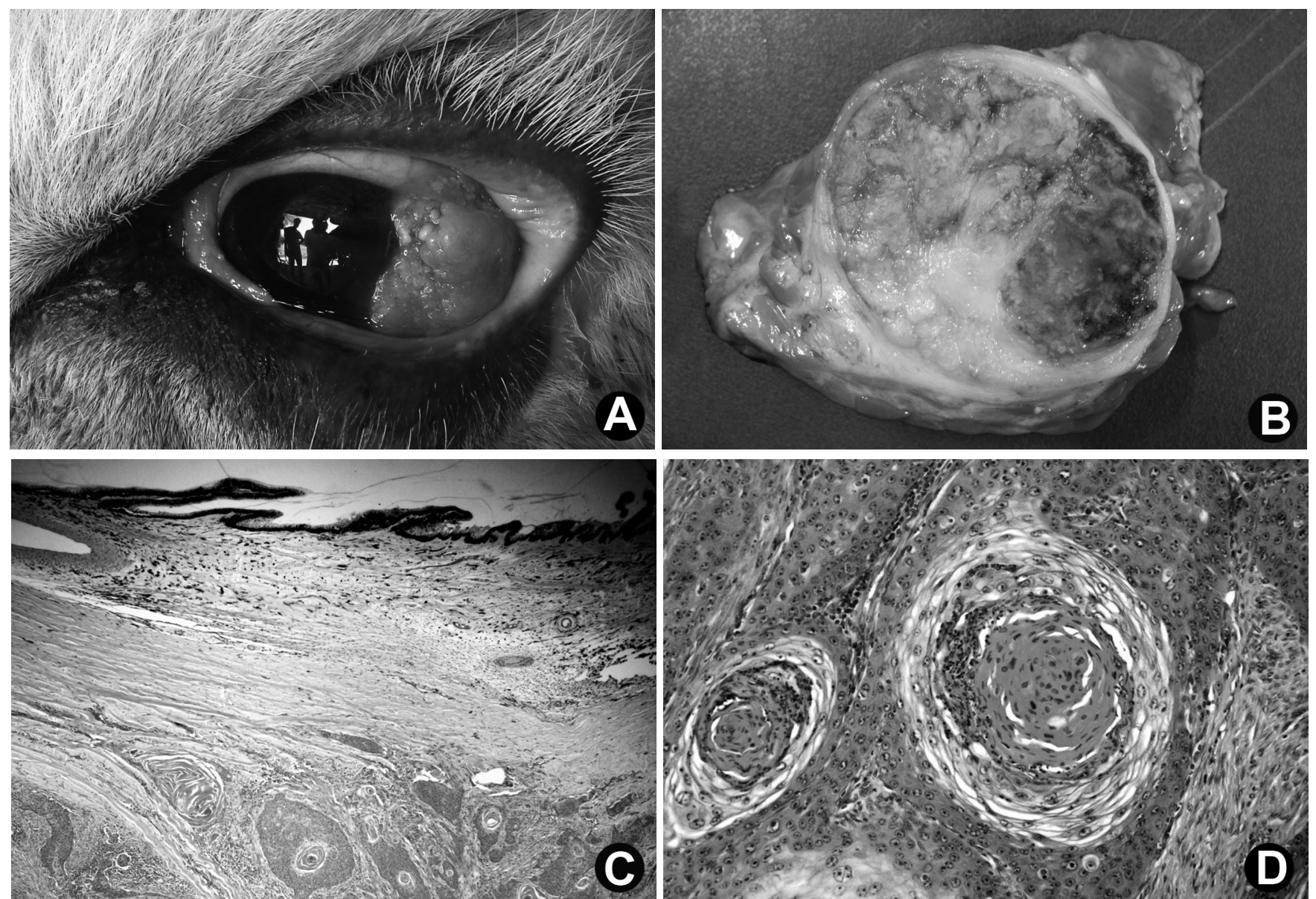

Fig.1. (A) Globo ocular de bovino apresentando carcinoma de células escamosas (CCE) na córnea. (B) Corte transversal da veia jugular de bovino com trombo neoplásico de CCE ocluindo a luz do vaso. (C) Ninhos de células tumorais característicos de CCE, formando pérolas de queratina, na córnea de bovino. HE, obj.10x. (D) CCE de pele bovino apresentando queratinização laminar concêntrica, formando pérolas de queratina. HE, obj.20x. 

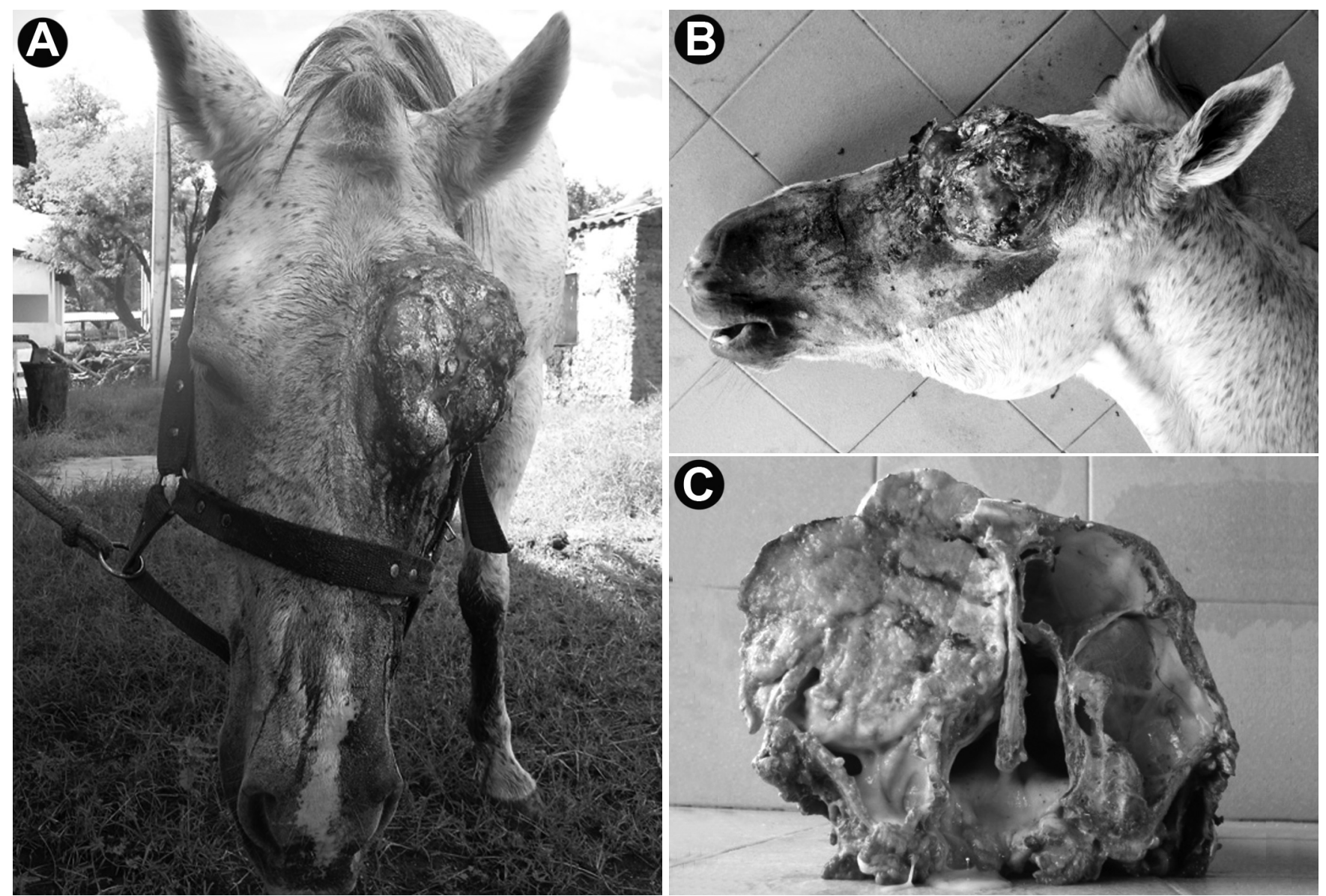

Fig.2. (A) Carcinoma de células escamosas (CCE) na região orbitária de equino, com perda do globo ocular. (B) CCE observado durante a necropsia de equino. (C) Corte transversal da cabeça de equino, mostrando infiltração do CCE nos seios frontais.

As frequências de CCE nas diferentes espécies em relação a sexo, idade e localização do tumor são apresentadas no Quadro 1. Em bovinos a análise de fatores de risco determinou uma maior frequência em fêmeas do que em machos $(p<0,001)$, e maior em adultos do que em jovens ou

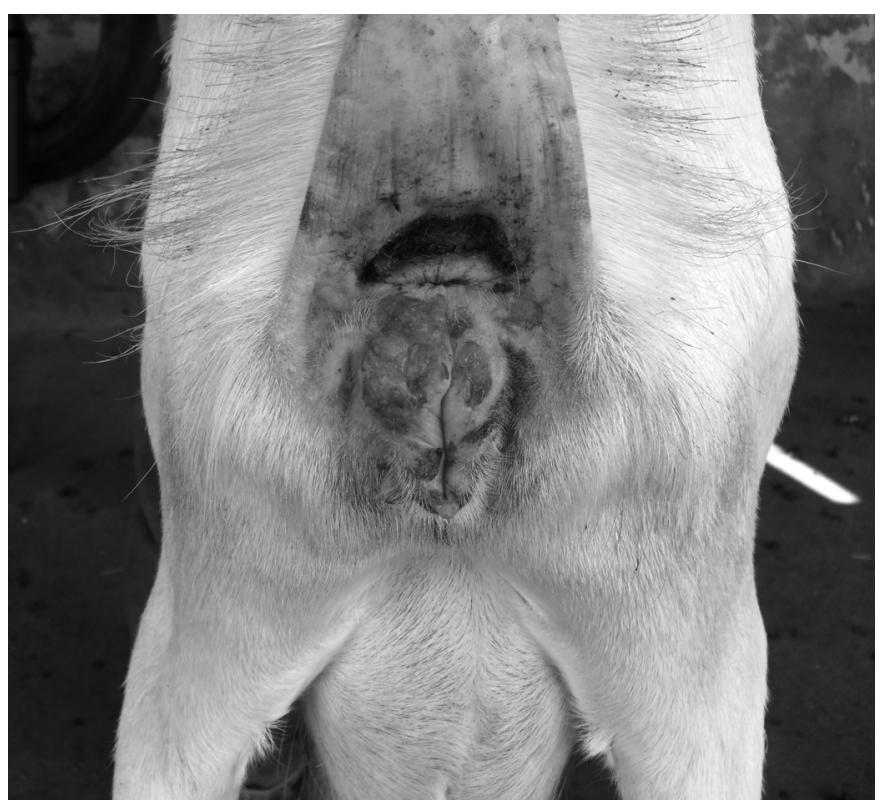

Fig.3. Vulva de cabra da raça Saanen com CCE. senis $(p<0,001)$. Nesta espécie a localização mais frequente do tumor foi no olho e pele periorbital $(p<0,001)$. Em caprinos observou-se maior frequência em fêmeas do que em machos ( $p=0,038)$, e maior em adultos do que em jovens ou

Quadro 1. Número de tumores em ruminantes e equinos distribuídos por sexo, idade e local do tumor, diagnosticados durante o período de janeiro de 1983 a dezembro de 2010.

\begin{tabular}{ccccc}
\hline & Bovinos & Equinos & Caprinos & Ovinos \\
\hline Sexo & & & & \\
Fêmea & 39 & 5 & 10 & 10 \\
Macho & 2 & 8 & - & 2 \\
$\mathrm{Ni}^{\mathrm{a}}$ & 1 & 2 & 2 & - \\
$\mathrm{P}^{\mathrm{b}}$ & $<0,001$ & 1,000 & 0,038 & 0,801 \\
Idade $_{\text {Jovem }}$ & 0 & & & \\
Adulto & 24 & 5 & - & 1 \\
Senil & 14 & 2 & - & 6 \\
$\mathrm{Ni}^{\mathrm{a}}$ & 4 & 4 & - & 1 \\
$\mathrm{P}^{\mathrm{b}}$ & $<0,001$ & 0,515 & 0,005 & 4 \\
Local & & & & 0,140 \\
Olho & 25 & 5 & 2 & 3 \\
$\mathrm{Pele}^{\mathrm{n}}$ & 10 & 4 & 1 & 7 \\
Rep. Masculino & - & 3 & 2 & - \\
Rep. Feminino & 6 & 1 & 6 & - \\
$\mathrm{Ni}^{\mathrm{a}}$ & 1 & 2 & 1 & 2 \\
$\mathrm{P}^{\mathrm{c}}$ & $<0,001$ & 0,442 & 0,147 & 0,018 \\
TOTAL & 42 & 15 & 12 & 12
\end{tabular}

a Não informado, ${ }^{\mathrm{b}}$ probabilidade (teste de qui-quadrado), ${ }^{\mathrm{c}}$ probabilidade (teste de qui-quadrado de aderência). 
Quadro 2. Número de tumores em ruminantes e equinos distribuídos por espécie e raça, diagnosticados durante o período de janeiro de 1983 a dezembro de 2010

\begin{tabular}{|c|c|c|c|c|c|c|c|}
\hline \multicolumn{2}{|c|}{ Bovinos $(n=42)$} & \multicolumn{2}{|c|}{ Equinos $(n=15)$} & \multicolumn{2}{|c|}{ Caprinos $(\mathrm{n}=12)$} & \multicolumn{2}{|c|}{ Ovinos $(\mathrm{n}=12)$} \\
\hline Raça & CCE (n) & Raça & CCE (n) & Raça & CCE (n) & Raça & CCE (n) \\
\hline Holandesa & 19 & Quarto de Milha & 4 & Saanen & 2 & Santa Inês & 4 \\
\hline Girolando & 2 & Paint Horse & 1 & Anglo Nubiano & 1 & $\mathrm{SRD}^{\mathrm{a}}$ & 5 \\
\hline $\mathrm{SRD}^{\mathrm{a}}$ & 20 & Manga-larga & 1 & Boer & 1 & $\mathrm{Ni}^{\mathrm{b}}$ & 3 \\
\hline \multirow[t]{3}{*}{$\mathrm{Ni}^{\mathrm{b}}$} & 1 & $\mathrm{SRD}^{\mathrm{a}}$ & 5 & Alpina & 1 & & \\
\hline & & $\mathrm{Ni}^{\mathrm{b}}$ & 4 & $\mathrm{SRD}^{\mathrm{a}}$ & 5 & & \\
\hline & & & & $\mathrm{Ni}^{\mathrm{b}}$ & 2 & & \\
\hline $\mathrm{P}^{\mathrm{c}}$ & $\mathrm{P}=0,479$ & $\mathrm{P}^{\mathrm{c}}$ & $P=0,392$ & $\mathrm{P}^{\mathrm{c}}$ & $\mathrm{P}=0,622$ & $\mathrm{P}^{\mathrm{c}}$ & $P=0,443$ \\
\hline
\end{tabular}

$\overline{{ }^{a}}$ Sem raça definida, ${ }^{\mathrm{b}}$ não informado, ${ }^{\mathrm{c}}$ probabilidade (teste de qui-quadrado).

senis $(\mathrm{p}<0,005)$. Em ovinos o tumor foi mais frequente na pele $(\mathrm{p}=0,018)$. Em equinos não foram encontrados fatores de risco para nenhuma das variáveis. Também não foram encontradas diferenças significantes entre as raças para nenhuma espécie (Quadro 2).

\section{DISCUSSÃO}

A frequência de CCE encontrada neste trabalho em ruminantes e equinos, de $2,6 \%$, foi semelhante à observada no Laboratório Regional de Diagnóstico da Faculdade de Veterinária da UFPel no Rio Grande do Sul, onde os CCEs tiveram frequência de 2,8\% em bovinos, ovinos e equinos (Ramos et al. 2008). Essa semelhança sugere que no Brasil não ocorrem diferenças significativas na frequência de CCEs em ruminantes e equinos devidas ao clima, pois mesmo duas regiões com climas tão diferentes tiveram frequências semelhantes. A região semiárida caracteriza-se por alta incidência de radiação solar intensa durante todo o ano (Medeiros \& Vieira 1997).

A ocorrência maior de CCE em bovinos deve-se provavelmente ao fato de que grande maioria dos animais examinados são de aptidão leiteira, das raças Holandesa e Girolando, que tem cruza com Holandês. Deve destacar-se, também, que dentre os bovinos SRD, há maioria tem cruzas de Holandês. As raças Hereford e Holandesa, por apresentarem pele clara, hipopigmentada, possuem predisposição a desenvolverem carcinomas, principalmente em olhos e tecidos periorbitais (Meuten 2002, Ramos et al. 2007). No caso de animais da raça Holandesa, a maior frequência pode estar também associada ao fato que, por tratar-se de raça leiteira, os rebanhos são constituídos principalmente por fêmeas mantidas nos rebanhos até o fim da vida produtiva, ao contrário dos machos, que são comercializados ou abatidos antes da idade adulta (Quadro 1). Na região há maior incidência dos raios solares durante longo período do ano e os animais de produção são criados extensivamente, favorecendo o surgimento desse tipo de neoplasia. Em outras regiões do Brasil, onde há ocorrência de Pteridium aquilinum (samambaia), os CCEs são mais frequentes no trato digestivo de bovinos (Lucena et al. 2011) e comumente vêm associados à papilomatose e infecção pelo papiloma vírus tipo 4 (Souto et al. 2006, Lucena et al. 2011).

Os equinos foram a espécie com a segunda maior frequência $(2,5 \%)$ de carcinomas de células escamosas não sendo encontrada diferenças significantes em relação aos fatores de risco analisados. Nesta espécie outros autores mencionam uma maior frequência de CCE no prepúcio do que em outros locais (Ramos et al. 2007).

Os caprinos, junto com os ovinos foram as espécies com menor frequência de CCE, de 1,5\% e 1,7\%, respectivamente, sendo que o único fator de risco, encontrado somente para os caprinos, foi a idade. Em caprinos, apesar de não haver diferenças significantes, o maior número de tumores, seis de um total de 12, foi localizado na vulva. Cabras Angora e Boer, por apresentarem pigmentação branca da região perineal desenvolvem mais frequentemente tumores nessa área (Smith \& Sherman 2009) o que provavelmente ocorre, também, com as cabras Saanen e suas cruzas. No estado de Minas Gerais o CCE é descrito acometendo a vulva de três cabras da raça Saanen (Melo et al. 1996), enquanto que no estado do Pará é descrito acometendo principalmente a região perineal de caprinos da raça Saanen e Boer (Barbosa et al. 2009).

Em ovinos a frequência de tumores pode ser considerada baixa não havendo diferenças entre as localizações. $\mathrm{Na}$ Paraíba a raça de ovinos predominante é a Santa Inês e atualmente, ao contrário do que ocorria anteriormente, a pelagem mais frequente é a preta. Para Macêdo et al. (2008) uma das causas da mudança na pigmentação da raça foi a alta frequência de carcinomas de células escamosas. Além da pigmentação da pele, outros fatores podem determinar altas frequências de tumores epidermoides em ovinos. No final da década de 70, no Rio Grande do Sul foram relatados 18 casos de CCE em um rebanho de 792 ovelhas adultas, localizados na cabeça, especificamente no focinho, orelha e olho. Os fatores determinantes dessa alta frequência teriam sido que os ovinos eram da raça Ideal (despigmentada) e o rebanho era constituído principalmente por ovelhas adultas, muitas de idade avançada (Riet-Correa et al. 1981). Uma frequência de 9,1\% de CCE de vulva foi observada em um rebanho de 33 ovelhas Ile de France, mencionando-se como possíveis fatores de risco a falta de pigmento da pele e junção muco-cutânea da vulva, pouca lã que apresenta essa raça na região perineal e o seccionamento demasiado da cauda (Riet-Correa \& Schild 1995). Outros fatores determinantes de alta frequência de CEE em ovinos são a ocorrência prévia de surtos de fotossensibilização (Lloyd 1961) e a realização da cirurgia de Mules, para evitar o acúmulo de matérias fecais na região perineal (Vandergraff 1976).

\section{CONCLUSÕES}

No semiárido da Paraíba do Brasil, os carcinomas de células escamosas ocorrem mais frequentemente em bovinos 
do que em equinos, ovinos ou caprinos, afetando, preferentemente, animais adultos.

Nos bovinos a localização preferencial é em olhos e região periocular, enquanto que nas outras espécies não foram encontradas diferenças significantes na localização do tumor.

Agradecimento- À Coordenação de Aperfeiçoamento de Pessoal de Nível Superior (CAPES), pela concessão da bolsa durante o Curso de Pós-Graduação.

\section{REFERÊNCIAS}

Barbosa J.D., Duarte M.D., Oliveira C.M.C., Reis A.B., Peixoto T.C., Peixoto P.V. \& Brito M.F. 2009. Carcinoma de células escamosas perineal em cabras no Pará. Pesq. Vet. Bras. 29(5):421-427.

Bastianello S.S. 1982. A survey on neoplasia in domestic species over a 40-year period from 1935 to 1974 in the republic of South Africa. I. Tumours occurring in cattle. Onderstepoort J. Vet. Res. 49:195-204.

Cotchin E. 1960. Tumours of farm animals: A survey of tumours examined at the Royal Veterinary College, London, during 1950-60. Vet. Rec. 72(40):816-822.

Dukes T.W., Bundza A. \& Corner A.H. 1982. Bovine neoplasms encountered in Canadian slaughterhouses: A summary. Can. Vet. J. 23:28-30.

Fernandes C.G. 2007. Neoplasias em ruminantes e equinos, p.650-656. In: Riet-Correa F., Schild A.L., Lemos R.A.A. \& Borges J.R.J. (Eds), Doenças de Ruminantes e Eqüinos. $3^{\mathrm{a}}$ ed. Pallotti, Santa Maria.

Lloyd L.C. 1961. Epithelial tumours of the skin of sheep. Brit. J. Cancer 15:780-789.

Lucena R.B., Pierezan F., Kommers G.D., Irigoyen L.F., Fighera R.A. \& Barros C.S.L. 2010. Doenças de bovinos no sul do Brasil: 6.706 casos. Pesq. Vet. Bras.30(5):428-434.

Lucena R.B., Rissi D.R., Kommers G.D., Pierezan F., Oliveira-Filho J.C., Macêdo J.T.S.A., Flores M.M. \& Barros C.S.L. 2011. A retrospective study of 586 tumours in Brazilian cattle. J. Comp. Pathol. 145:20-24.

Macêdo J.S.A., Riet-Correa F., Dantas A.F.M. \& Simões S.V.D. 2008. Doenças da pele em caprinos e ovinos no semi-árido brasileiro. Pesq. Vet. Bras.28(12):633-642.

Medeiros L.F.D. \& Vieira D.H. 1997. Boclimatologia Animal. Instituto de Zootecnia, Universidade Federal Rural do Rio de Janeiro, Seropédica, RJ. 126p.

Melo M.M., Serakides R., Souza J.C.A., Guedes R.M.C., Nogueira R.H.G. \& Alzamora Filho F. 1996. Carcinoma espinocelular de vulva em caprinos: relato de três casos. Anais XV Encontro de Pesquisa da Escola de Veterinária da UFMG, Belo Horizonte, p.35.

Meuten D.J. 2002. Tumors in Domestic Animals. $4^{\text {th }}$ ed. State Press, Ames, Iowa, p.45-118.
Misdorp W. 1967. Tumours in large domestic animals in the Netherlands. J. Comp. Pathol. 77: 211-216.

Murray M. 1968. Neoplasms of domestic animals in East Africa. Brit. Vet. J. 124:514-524.

Plummer P.J.G. 1956. A survey of six hundred and thirty six tumours from domesticated animals. Can. J. Comp. Med. 20(7):239-251.

Ramos A.T., Norte D.M., Elias F. \& Fernandes C.G. 2007. Carcinoma de células escamosas em bovinos, ovinos e equinos: estudo de 50 casos no sul do Rio Grande do Sul. Braz. J. Vet. Res. Anim. Sci., São Paulo, 44(Supl.):513.

Ramos A.T., Souza A.B., Norte D.M., Ferreira J.L.M. \& Fernandes C.G. 2008. Tumores em animais de produção: aspectos comparativos. Ciência Rural 38(1):148-154.

Riet-Correa F., Cassal A.B., Scarsi R.M., Schild A.L. \& Mendez M.C. 1981. Carcinomas epidermóides em ovinos em um estabelecimento do Rio Grande do Sul. Pesq. Vet. Bras. 1(2):65-68.

Riet-Correa F. \& Schild A.L. 1995. Doenças diagnosticadas pelo Laboratório Regional de Diagnóstico no ano de 1994 e comentários sobre algumas doenças. Bolm Lab. Regional Diagn., Pelotas, 15:8-20.

Scott D.W. \& Miller Jr W.H. 2011. Equine Dermatology. $2^{\text {nd }}$ ed. Elsevier Saunders, Maryland Heights, Missouri, p.468-516.

Smith B.P. 2006. Medicina interna de grandes animais. $3^{\underline{a}}$ ed. Editora Manole, São Paulo, p.892-895.

Smith M.C. \& Sherman D.M. 2009. Goat medicine. $2^{\text {nd }}$ ed. Wiley-Blackwell, Ames, Iowa. 869p.

Souto M.A.M., Kommers G.D., Barros C.S.L., Piazer J.V.M., Rech R.R., Riet-Correa F. \& Schild A.L. 2006. Neoplasias do trato alimentar superior de bovinos associadas ao consumo espontâneo de samambaia (Pteridium aquilinum). Pesq. Vet. Bras. 26(2):112-122.

Souza T.M., Brum J.S., Fighera R.A., Brass K.E. \& Barros C.S.L. 2011. Prevalência dos tumores cutâneos de equinos diagnosticados no Laboratório de Patologia Veterinária da Universidade Federal de Santa Maria, Rio Grande do Sul. Pesq. Vet. Bras. 31(5):379-382.

Tsujita H. \& Plummer C.E. 2010. Bovine ocular squamous cell carcinoma. Vet. Clin. Food Anim. 26:511-529.

Valentine B.A. 2006. Survey of equine cutaneous neoplasis in the Pacific Northwest. J. Vet. Diagn. Invest. 18:123-126.

Vandergraff R. 1976. Squamous cell carcinoma of the vulva in Merino sheep. Aust. Vet. J. 52:21-23.

Weiss E. \& Frese K. 1974. International Histological Classification of Tumors of Domestic Animals: Tumours of the skin. Bull. World Health Organization 50(1/2):79-100.

Yeruham I., Perl S., Orgad U. \& Yakobson B. 1999. Tumours of the vulva and vagina in cattle: A 10-year survey. Vet. Journal 158:237-239. 